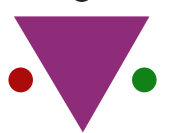

IJCRR

Section: Healthcare

Sci. Journal Impact

Factor: 6.1 (2018)

ICV: 90.90 (2018)

(c) (i) (8)

Copyright@IJCRR

\section{Awareness on Spread of Misinformation and its Effect on Public with Regard to COVID-19}

\section{Swetha Ramasubramanian1, Preetha S' ${ }^{2}$ Dinesh Premavathy3 ${ }^{3}$ Lavanya Prathap ${ }^{4}$}

Saveetha Dental College, Saveetha Institute of Medical and Technical Sciences, Saveetha University, Chennai, India; ${ }^{2}$ Senior Lecturer, Department of Physiology, Saveetha Dental College, Saveetha Institute of Medical and Technical Sciences, Saveetha University, Chennai, India; ${ }^{3}$ enenior Lecturer, Department of Anatomy, Saveetha Dental College, Saveetha Institute of Medical and Technical Sciences, Saveetha University, Chennai, India; ${ }^{4}$ Assistant Professor, Department of Anatomy, Saveetha Dental College, Saveetha Institute of Medical and Technical Sciences, Saveetha University, Chennai, India.

\title{
ABSTRACT
}

Introduction: Misinformation can amplify humanity's greatest challenges. A salient example of this is the COVID-19 pandemic, which has spread a wide range of falsehoods even as truth has more and more turned into a matter of life and death. In the current study, the aim is to analyze the effect of social media on the public with regard to COVID-19.

Materials and Methods: A survey was conducted among 100 participants [79 male, 21 female]. 13 questions were circulated through online Google forms via WhatsApp platform. Responses were collected and verified.

Result: On analyzing the data majority of the participants used WhatsApp and Facebook for news updates regarding COVID-19, $46 \%$ were aware of authentic websites to cross-check the news and $77 \%$ of the participants agreed that they get disturbed with a lot of information related to COVID-19.

Conclusion: Thus we conclude that strict measures must be taken to prevent the spread of misinformation and to avoid mental health problems.

Key Words: Awareness, Social media, Coronavirus, Misinformation, Pandemic, Fake news.

\section{INTRODUCTION}

The World Health Organization (WHO) described the SARS$\mathrm{CoV}-2$ virus (initially known as $2019-\mathrm{nCoV}$ ) outbreak as a severe global threat ${ }^{12}$. This kind of global pandemic provokes different sets of reactions from people depending on cultural orientations. Media communication may display either accurate or effective information to inform the public. At the same time, it can also misinform and further add to unnecessary public panic and lead to undesirable responses ${ }^{3}$. One of the causes of this panic is that the information from the experts was not disseminated enough to reach the community at the appropriate time ${ }^{4}$. Social media platforms contribute direct access to an unprecedented load of content and may intensify rumors and questionable information. Taking into account users' preferences and attitudes, algorithms mediate and facilitate content promotion and hence spreading of information ${ }^{5}$. This shift of paradigm profoundly influences the construction of social perceptions ${ }^{6}$ and the framing of narratives; it affects policy-making, political communication, also the evolution of public debate ${ }^{7,8}$ particularly when issues are controversial ${ }^{9}$.

Social media platforms are extensively used by people to forward information in different situations ${ }^{10}$. At the time of a crisis, rich situational information is generated by social media users ${ }^{11}$. Both the impact of the disease along with the lack of information allowed medical misinformation to rapidly surface and spread on different social media platforms. Previous studies have shown a similar trend during recent public health emergencies, mainly the Ebola and Zika outbreaks ${ }^{12}$. Misinformation can be described as a "claim of fact that is currently false due to lack of scientific evidence" ${ }^{13}$. This makes it ideal to disseminate through social media and become amplified by the information silos and echo chambers of personally tailored content, especially during times of public tension like the current COVID-19 epidemic 14.

\section{Corresponding Author:}

Preetha S, Lecturer, Department of Physiology, Saveetha Dental College, Saveetha Institute of Medical and Technical Sciences, Saveetha University, 160, Poonamallee High Rd, Velappanchavadi, Chennai 600077, Tamil Nadu, India; Phone: +91 86085 66435; Email: preethas. sdc@saveetha.com

ISSN: 2231-2196 (Print)

Received: 25.07 .2020
ISSN: $0975-5241$ (Online)

Revised: 27.08 .2020
Accepted: 22.09 .2020
Published: 20.10 .2020 
Several studies were done by the students in our department but this study is the first of its kind ${ }^{15-22}$. The aim of the present study is to analyze the influence of social media among the general public during the pandemic.

\section{MATERIALS AND METHODS}

An online survey of 100 people was conducted to analyze the effect of the general public with regard to COVID-19. The approval for conducting the survey was obtained from the esteemed institutional research department via SRB. Self-administered questionnaires (set of 13) were circulated. The questions were framed based on the source used by the participants for news updates related to COVID-19, awareness about authentic websites to verify the information, and the effect of misinformation related to COVID-19. The participants were advised to read the questions thoroughly and then begin to answer the questions. The data were validated and verified. Feedback and corrections from the participants were taken into account.

\section{Questionnaire:}

1. What is your gender?

2. Which media source do you use for new updates?

3. Is the news source you refer, reliable?

4. Do you know any authentic websites that are available, to verify news regarding COVID-19?

5. Are you aware of any govt websites to verify information?

6. Do you cross-check the news you come across?

7. Are you aware that many fake news are spread through WhatsApp and Facebook?

8. Do you get frustrated with a lot of news regarding COVID-19?

9. Do you experience stress and depression on the spread of misinformation regarding COVID-19?

10. Do you get mentally disturbed by misinformation related to COVID-19 on social media?

11. Do you read only the headline (or) read the entire article?

12. Do you know that the headlines are displayed mostly for attraction rather than providing the information?

13. Do you think that people spreading fake news have to be punished?

The data collection was done through Google forms https:// docs.google.com/forms/u/0/ and data manipulation through MS Excel. The data obtained were plotted in the form of a bar graph.

\section{Statistical Analysis}

The results were converted to a spreadsheet and then converted to SPSS software and were statistically analyzed, correlation was done using Chi-square test.

\section{RESULTS AND DISCUSSION}

On analyzing the data, $41 \%$ of the participants were male and $59 \%$ of the participants were female (Figure 1). $53 \%$ of the participants used WhatsApp, 20\% of the participants used Facebook, $11 \%$ of the participants used T.V, 5\% of the participants used Twitter and $11 \%$ of the participants used other sources for news updates (Figure 2). $85 \%$ of the participants agreed that the news sources they referred to were reliable (Figure 3). $46 \%$ of the participants knew authentic websites that are available to verify news regarding COVID-19 while $54 \%$ were unaware (Figure 4). 44\% were aware of government websites to verify information regarding COVID-19 (Figure 5). $78 \%$ of the participants accepted that they crosscheck the news related to COVID-19 (Figure 6). 88\% were aware that most of the fake news was spread through social media (Figure 7). $77 \%$ of the participants felt frustrated with a lot of news regarding COVID-19 (Figure 8). The majority of the participants i.e. $83 \%$ felt that the news projected through broadcast media such as television and other platforms affects the news in print media (Figure 9). $48 \%$ of participants revealed that they get mentally disturbed due to misinformation related to COVID-19 on social media (Figure 10). $79 \%$ admitted that they read only headlines while $21 \%$ read the entire article (Figure 11). $85 \%$ of the participants knew that the headlines are displayed mostly for attraction rather than providing information (Figure 12). 88\% agreed that people spreading fake news have to be punished (Figure 13).

The study presents that $23 \%$ of the Male and $31 \%$ of the Female used WhatsApp, $7 \%$ of the Male and $12 \%$ of the Female used Facebook, 3\% of the Male and $8 \%$ of the Female used T.V and $3 \%$ of the males and $8 \%$ of the females used other sources for news updates related to COVID-19 (Figure 14). $16 \%$ of the males and $30 \%$ of the females were aware of authentic websites to verify news related to COVID-19 (Figure 15). 36\% of the males and 50\% of the females were aware that fake news was spread mostly through social media (Figure 16). $28 \%$ of the males and $49 \%$ of the females were frustrated due to a lot of news updates related to COVID-19 (Figure 17).

On observing the result $53 \%$ of the participants used WhatsApp, $20 \%$ of the participants used Facebook, $11 \%$ of the participants used T.V, $5 \%$ of the participants used Twitter and $11 \%$ of the participants used other sources for news updates related to COVID-19. In a study conducted by Toan Luu Duc Huynh (2020) among 391 participants $24.55 \%$ referred to the newspaper, magazine, and television; $62.4 \%$ from social media such as Facebook and Zalo4; and the rest from other sources ${ }^{23} .85 \%$ of the participants felt that the news sources they referred were reliable while $15 \%$ did not. In a similar study conducted by Toan Luu Duc Huynh (2020) 11\% of the respondents did not search for information on COVID-19 constantly, while the majority of the respondents, $80 \%$ ac- 
cepted that they searched at least twice a day ${ }^{23} .46 \%$ of the participants were aware of authentic websites that are available to verify news regarding COVID-19, while $54 \%$ were unaware. In a study by Pennycook et al. false headlines were considered to be false by authoritative sources such as factchecking sites like snopes.com and factcheck.org, health experts such as mayoclinic.com, and credible science websites such as www.livescience.com. The true headlines appeared from reliable mainstream media sources ${ }^{24}$. Previous studies on why people share and spread misinformation or fake news on social media have reported several explanations, of which high trust in online sources is pertinent ${ }^{25}$. People form different decisions about information when driven by fear and anxiety ${ }^{26}$. As an example, there is evidence that seeking information during pandemics is more common among those experiencing worry or fear ${ }^{27}$. Similarly, previous studies show that when in a state of fear or distress, peoples' usage patterns and perceptions of social media vary significantly to the extent they can become overloaded and fatigued ${ }^{28}$.

$86 \%$ of the participants were aware that much fake news was spread through social media while $14 \%$ were unaware. Whether people forward the fake news articles in social media is determined by the relevance, shock value, and believability of the information rather than its source ${ }^{29}$. Furthermore, lack of experience about online environments and resulting trust in online information, also laziness in verifying the information source and lack of skills to do it, are reasons that cause people to share misinformation ${ }^{30}$. $48 \%$ of the participants felt mentally disturbed by misinformation related to COVID-19 on social media while $52 \%$ did not. Social media may promote (mis)information overload ${ }^{31}$, which in turn may result in mental health problems. The mental disturbance may in turn affect the sleep cycle ${ }^{32}$. WHO indicated that identifying the underlying drivers of fear, anxiety, and stigma that fuel misinformation and rumor, especially via social media ${ }^{33}$. Previous studies revealed that indirect exposure to mass trauma through the media can enhance the initial rates of post-traumatic stress disorder (PTSD) symptoms ${ }^{34}$. Stress may in turn result in the release of certain hormones that can affect the regular functioning of our body ${ }^{35,36,37}$. Stress can hence cause severe heart problems ${ }^{38}$, as well as affect the individuals with respiratory disorders ${ }^{39,40}$. A previous study also indicated that social media exposure may directly be associated with developing risk perceptions during the MERS outbreak in South Korea ${ }^{41} .85 \%$ of the participants were aware that the headlines are displayed mostly for attraction rather than provide the information, while $15 \%$ were unaware. Lack of information and misinformation, often fueled by exaggerated popular media headlines and foci, have been reported to reinforce health-related fears and phobias ${ }^{42}$.

\section{CONCLUSION}

Misinformation spread rapidly through social media platforms and brings about mental health problems among the general public. The government must take legal action against those spreading misinformation. Thus it will reduce community panic and aid in receiving precise information through media communication.

\section{ACKNOWLEDGEMENT}

This research was done under the supervision of the Department of Research of Saveetha Dental College and Hospitals. We sincerely show gratitude to the Institution who provided insight and expertise that greatly assisted the research.

\section{Conflict of Interest}

Nil

\section{Funding Information}

None

\section{REFERENCES}

1. Smith J. The World Social Forum and the challenges of global democracy [Internet]. Vol. 4, Global Networks. 2004. p. 413-21. Available from: http://dx.doi.org/10.1111/j.14710374.2004.00102.x

2. Koley TK, Dhole M. ORIGIN Spread and global response to COVID-19 [Internet]. The COVID-19 Pandemic. 2020. p. 3467. Available from: http://dx.doi.org/10.4324/9781003095590-4

3. Jones SC, Waters L, Holland O, Bevins J, Iverson D. Developing pandemic communication strategies: Preparation without panic [Internet]. Vol. 63, Journal of Business Research. 2010. p. 126-32. Available from: http://dx.doi.org/10.1016/j.jbusres.2009.02.009

4. Greco P. Pandemic: how to avoid panic? [Internet]. Vol. 04, Journal of Science Communication. 2005. Available from: http://dx.doi.org/10.22323/2.04040501

5. Kulshrestha J, Eslami M, Messias J, Zafar MB, Ghosh S, Gummadi KP, et al. Quantifying Search Bias [Internet]. Proceedings of the 2017 ACM Conference on Computer Supported Cooperative Work and Social Computing. 2017. Available from: http:// dx.doi.org/10.1145/2998181.2998321

6. Schmidt AL, Zollo F, Del Vicario M, Bessi A, Scala A, Caldarelli G, et al. Anatomy of news consumption on Facebook [Internet]. Vol. 114, Proceedings of the National Academy of Sciences. 2017. p. 3035-9. Available from: http://dx.doi.org/10.1073/ pnas. 1617052114

7. Starnini M, Frasca M, Baronchelli A. Emergence of metapopulations and echo chambers in mobile agents. Sci Rep. 2016 Aug 30;6:31834.

8. Schmidt AL, Zollo F, Scala A, Betsch C, Quattrociocchi W. Polarization of the vaccination debate on Facebook. Vaccine. 2018 Jun 14;36(25):3606-12.

9. Vicario MD, Del Vicario M, Bessi A, Zollo F, Petroni F, Scala $\mathrm{A}$, et al. The spreading of misinformation online [Internet]. Vol. 113, Proceedings of the National Academy of Sciences. 
2016. p. 554-9. Available from: http://dx.doi.org/10.1073/ pnas. 1517441113

10. Wang F-Y, Zeng D, Zhang Q, Hendler JA, Cao J. The Chinese "Human Flesh" Web: the first decade and beyond [Internet]. Vol. 59, Chinese Science Bulletin. 2014. p. 3352-61. Available from: http://dx.doi.org/10.1007/s11434-014-0480-6

11. Rudra K, Ghosh S, Ganguly N, Goyal P, Ghosh S. Extracting Situational Information from Microblogs during Disaster Events [Internet]. Proceedings of the 24th ACM International on Conference on Information and Knowledge Management - CIKM '15. 2015. Available from: http://dx.doi. org/10.1145/2806416.2806485

12. Miller M, Banerjee T, Muppalla R, Romine W, Sheth A. What Are People Tweeting About Zika? An Exploratory Study Concerning Its Symptoms, Treatment, Transmission, and Prevention. JMIR Public Health Surveill. 2017 Jun 19;3 (2):e38.

13. Chou W-YS, Oh A, Klein WMP. Addressing Health-Related Misinformation on Social Media. JAMA. 2018 Dec 18;320 (23):2417-8.

14. Zarocostas J. What next for the coronavirus response? Lancet. 2020 Feb 8;395(10222):401.

15. Samuel AR, Devi MG. Geographical distribution and occurrence of Endemic Goitre [Internet]. Vol. 8, Research Journal of Pharmacy and Technology. 2015. p. 973. Available from: http:// dx.doi.org/10.5958/0974-360x.2015.00162.6

16. Baheerati MM, Gayatri Devi R. Obesity in relation to Infertility [Internet]. Vol. 11, Research Journal of Pharmacy and Technology. 2018. p. 3183. Available from: http://dx.doi. org/10.5958/0974-360x.2018.00585.1

17. Fathima F, Preetha P. EVALUATION OF THYROID FUNCTION TEST IN OBESE PATIENTS [Internet]. Vol. 9, Asian Journal of Pharmaceutical and Clinical Research. 2016. p. 353. Available from: http://dx.doi.org/10.22159/ajpcr.2016. v9s3.12959

18. Harsha L, Priya J, Shah KK, Reshmi B. Systemic Approach to Management of Neonatal Jaundice and Prevention of Kernicterus [Internet]. Vol. 8, Research Journal of Pharmacy and Technology. 2015. p. 1087. Available from: http://dx.doi. org/10.5958/0974-360x.2015.00189.4

19. Shruthi M, Preetha S. Effect of Simple Tongue Exercises in Habitual Snorers [Internet]. Vol. 11, Research Journal of Pharmacy and Technology. 2018. p. 3614. Available from: http://dx.doi. org/10.5958/0974-360x.2018.00665.0

20. David, David, Jothi Priya A, Devi G. Physical Fitness among the Dental Physician, Dental Undergraduates and Postgraduates Students [Internet]. Vol. 10, Indian Journal of Public Health Research \& Development. 2019. p. 223. Available from: http:// dx.doi.org/10.5958/0976-5506.2019.02801.8

21. Abigail, Abigail, Priya J, Devi G. Evaluation of Muscular Endurance among Dentists [Internet]. Vol. 10, Indian Journal of Public Health Research \& Development. 2019. p. 258. Available from: http://dx.doi.org/10.5958/0976-5506.2019.02808.0

22. Swathy S, Gowri Sethu V. Acupuncture and lower back pain [Internet]. Vol. 8, Research Journal of Pharmacy and Technology. 2015. p. 991. Available from: http://dx.doi.org/10.5958/0974360x.2015.00165.1

23. Huynh TLD. Data for understanding the risk perception of COVID-19 from Vietnamese sample. Data Brief. 2020 Jun;30:105530.

24. Pennycook G, McPhetres J, Zhang Y, Rand DG. Fighting COVID-19 misinformation on social media: Experimental evidence for a scalable accuracy nudge intervention [Internet]. Available from: http://dx.doi.org/10.31234/osf.io/uhbk9

25. Talwar S, Dhir A, Kaur P, Zafar N, Alrasheedy M. Why do people share fake news? Associations between the dark side of social media use and fake news sharing behavior [Internet]. Vol. 51, Journal of Retailing and Consumer Services. 2019. p. 72-82. Available from: http://dx.doi.org/10.1016/j.jretconser.2019.05.026

26. Pettit S, Beresford A. Port Management: Cases in Port Geography, Operations and Policy. Kogan Page Publishers; 2017. 576 p.

27. Ephross S. Sumatriptan exposure during pregnancy: what have we learned about the risk of birth defects?* [Internet]. Vol. 101, Obstetrics \& Gynecology. 2003. p. S83-4. Available from: http://dx.doi.org/10.1016/s0029-7844(02)02957-5

28. Maier C, Laumer S, Eckhardt A, Weitzel T. Giving too much social support: social overload on social networking sites [Internet]. Vol. 24, European Journal of Information Systems. 2015. p. 447-64. Available from: http://dx.doi.org/10.1057/ejis.2014.3

29. Chen X, Sin S-CJ, Theng Y-L, Lee CS. Why Students Share Misinformation on Social Media: Motivation, Gender, and Study-level Differences [Internet]. Vol. 41, The Journal of Academic Librarianship. 2015. p. 583-92. Available from: http:// dx.doi.org/10.1016/j.acalib.2015.07.003

30. Khan ML, Laeeq Khan M, Idris IK. Recognise misinformation and verify before sharing: a reasoned action and information literacy perspective [Internet]. Vol. 38, Behaviour \& Information Technology. 2019. p. 1194-212. Available from: http://dx.doi.or g/10.1080/0144929x.2019.1578828

31. Poghosyan G. Addressing Information Overload through Text Mining across News and Social Media Streams [Internet]. Proceedings of the 5th International Workshop on Social Media World Sensors - SIdEWayS'19. 2019. Available from: http:// dx.doi.org/10.1145/3345645.3351105

32. $\mathrm{Rj} \mathrm{I}, \mathrm{R}$ GD. Role of environmental factors on sleep patterns of different age groups [Internet]. Vol. 9, Asian Journal of Pharmaceutical and Clinical Research. 2016. p. 124. Available from: http://dx.doi.org/10.22159/ajpcr.2016.v9i6.13832

33. World experts and funders set priorities for COVID-19 research [Internet]. [cited 2020 Jun 3]. Available from: https://www.who. $\mathrm{int} /$ news-room/detail/12-02-2020-world-experts-and-fundersset-priorities-for-covid-19-research

34. Neria Y, Sullivan GM. Understanding the mental health effects of indirect exposure to mass trauma through the media. JAMA. 2011 Sep 28;306(12):1374-5.

35. Iyer PK, Gayatri Devi R, Jothi Priya A. A Survey Study on Causes, Treatment and Prevention of Onychocryptosis [Internet]. Vol. 10, Indian Journal of Public Health Research \& Development. 2019. p. 807. Available from: http://dx.doi.org/10.5958/09765506.2019.01990.9

36. R GD, Sethu G. EVALUATION OF ADENOIDS BY ORONASAL AND NASAL SPIROMETRY [Internet]. Vol. 11, Asian Journal of Pharmaceutical and Clinical Research. 2018. p. 272. Available from: http://dx.doi.org/10.22159/ajpcr.2018. v11i10.27365

37. Choudhari S, Jothipriya MA. Non-alcoholic fatty liver disease [Internet]. Vol. 9, Research Journal of Pharmacy and Technology. 2016. p. 1782. Available from: http://dx.doi.org/10.5958/0974360x.2016.00360.7

38. Renuka S, Sethu G. Regeneration after Myocardial Infarction [Internet]. Vol. 8, Research Journal of Pharmacy and Technology. 2015. p. 738. Available from: http://dx.doi.org/10.5958/0974360x.2015.00117.1

39. Dave PH, Preetha. Pathogenesis and Novel Drug for Treatment of Asthma-A Review [Internet]. Vol. 9, Research Journal of Pharmacy and Technology. 2016. p. 1519. Available from: http:// dx.doi.org/10.5958/0974-360x.2016.00297.3 
40. Timothy CN, Gayatri Devi R, Jothi Priya A. Evaluation of Peak Expiratory Flow Rate (PEFR) in Pet Owners [Internet]. Vol. 10, Indian Journal of Public Health Research \& Development. 2019. p. 803. Available from: http://dx.doi.org/10.5958/09765506.2019 .01989 .2

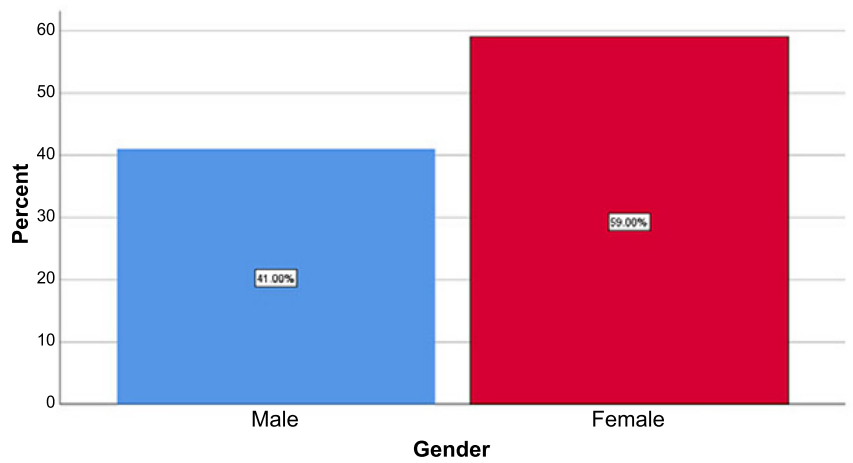

Figure 1: The bar chart depicting the percentage distribution of gender among the participants. $X$-axis represents gender and $Y$-axis denotes the percentage of respondents. $21 \%$ of the participants were male (blue) and $79 \%$ of the participants were female (red).

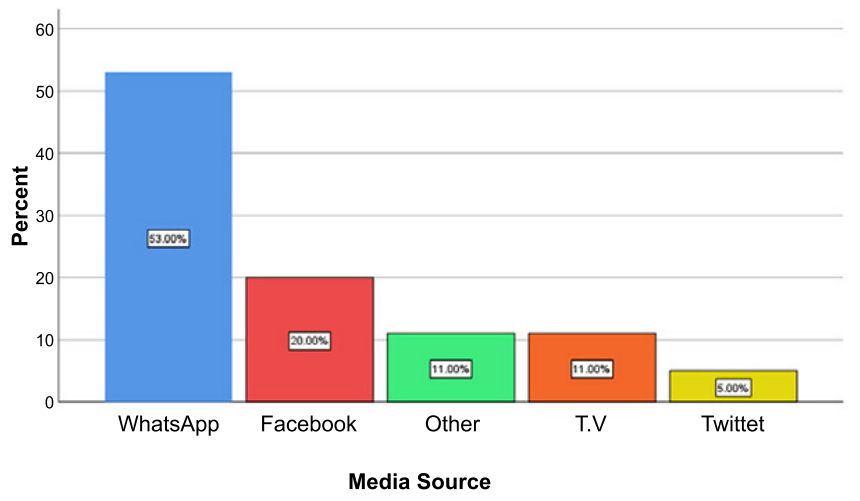

Figure 2: The bar chart represents the percentage distribution of the response regarding the media source used by the participants for news updates related to COVID-19. X-axis represents responses and $\mathrm{Y}$-axis represents the percentage of responses. $53 \%$ of the participants used WhatsApp (blue), $20 \%$ of the participants used Facebook (red), $11 \%$ of the participants used T.V (other), $5 \%$ of the participants used Twitter (yellow) and $11 \%$ of the participants used other sources (orange).
41. Choi D-H, Yoo W, Noh G-Y, Park K. The impact of social media on risk perceptions during the MERS outbreak in South Korea. Comput Human Behav. 2017 Jul;72:422-31.

42. Taylor S, Asmundson GJG. Treating Health Anxiety: A Cognitive-behavioral Approach. Guilford Press; 2004. 299 p.

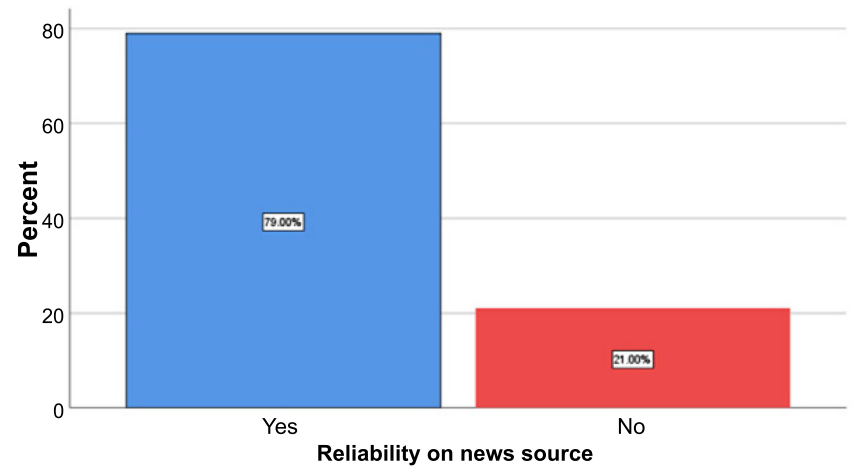

Figure 3: The bar chart represents the percentage distribution regarding the reliability of news sources by the participants. $X$ axis denotes the reliability of the news sources and $Y$-axis denotes the percentage of respondents. $79 \%$ of the participants agreed that the news source they referred were reliable (blue) while $21 \%$ of the participants did not agree (red).

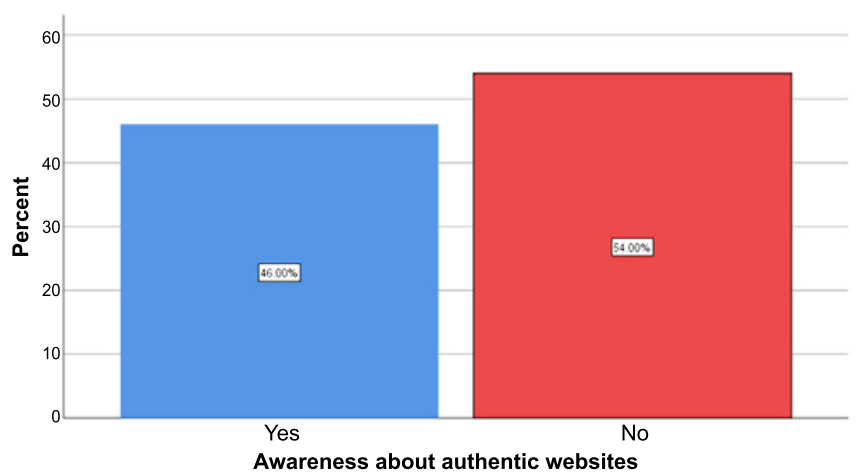

Figure 4: The bar chart represents the percentage distribution regarding awareness of authentic websites among the participants to verify news regarding COVID-19. X-axis denotes awareness about authentic websites and $\mathrm{Y}$-axis denotes the percentage of respondents. $46 \%$ of the participants were aware (blue) of authentic websites while $54 \%$ of the participants were unaware (red). 


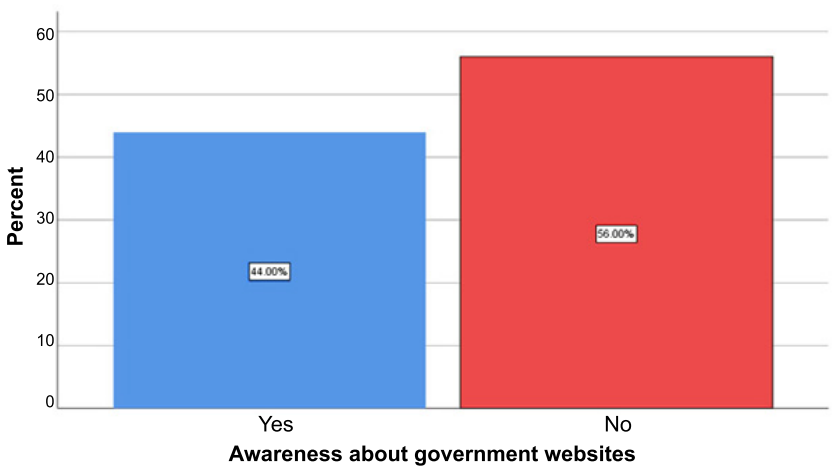

Figure 5: The bar chart represents the percentage awareness of government websites among the participants to verify news regarding COVID-19. X-axis denotes awareness about government websites and $\mathrm{Y}$-axis denotes the percentage of respondents. $44 \%$ of the participants were aware of the government website (blue) while $56 \%$ of the participants were unaware (red).

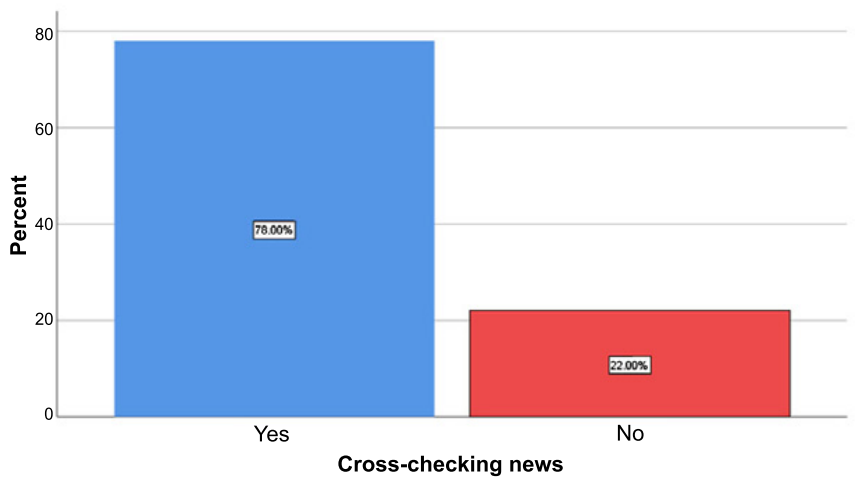

Figure 6: The bar chart represents the response regarding the cross verifying the news related to COVID-19. X-axis denotes responses and $\mathrm{Y}$-axis denotes the percentage of respondents. $78 \%$ of the participants cross-checked the news related to COVID-19 (blue) $22 \%$ of the participants did not cross-check (red).

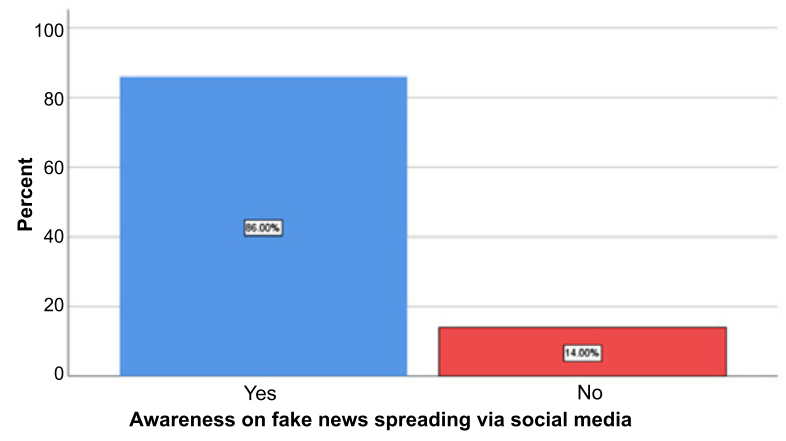

Figure 7: The bar chart represents the percentage distribution of responses regarding the spread of fake news is mostly through social media. $X$-axis denotes awareness about the spread of fake news through social media and Y-axis denotes the percentage of respondents. $86 \%$ of the participants were aware that fake news spread mostly through social media (blue) while $14 \%$ were unaware (red).

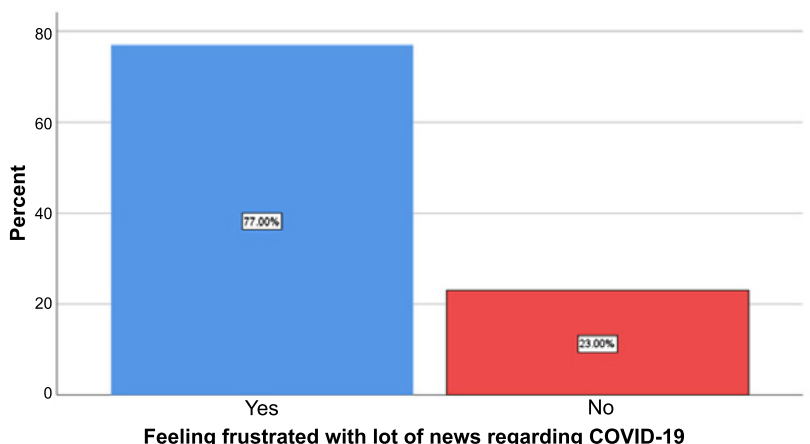

Figure 8: The bar chart represents the percentage distribution of response regarding the frustration undergone by the participants due to continuous news updates regarding COVID-19. $\mathrm{X}$-axis denotes responses and $\mathrm{Y}$-axis denotes the percentage of respondents. $77 \%$ of the participants agreed that they get frustrated with a lot of news related to COVID-19 (blue) and $23 \%$ of the participants did not (red).

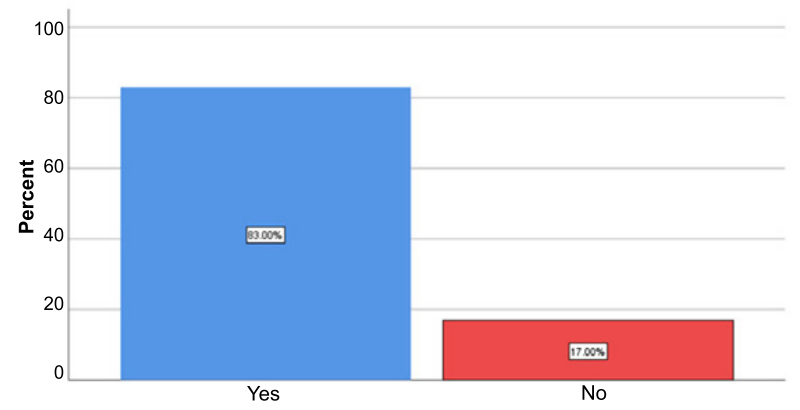

Figure 9: The bar chart represents the percentage distribution of response regarding the participants experiencing stress and depression on the spread of misinformation regarding COVID-19. X-axis denotes responses and Y-axis denotes the percentage of respondents. $83 \%$ of the participants agreed that the news presented in broadcast media affects the news in print media (blue) while $17 \%$ of the participants did not agree (red).

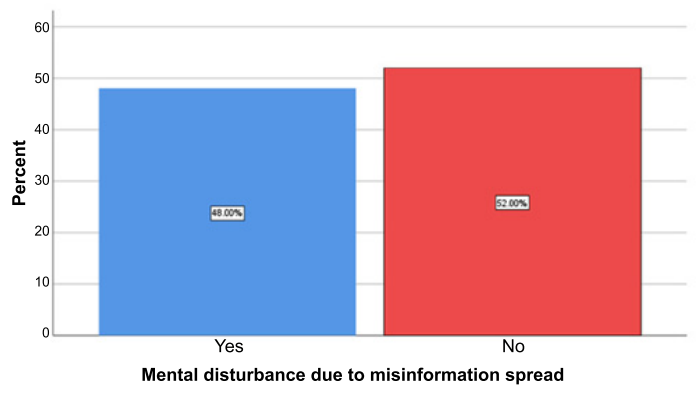

Figure 10: The bar chart represents the response regarding the mental disturbance experienced by the participants due to the spread of misinformation related to COVID-19 on social media. X-axis denotes responses and $\mathrm{Y}$-axis denotes the percentage of respondents. $48 \%$ of the participants admitted that they get mentally disturbed due to the spread of misinformation related to COVID-19 on social media (blue) and $52 \%$ of the participants did not get mentally disturbed (red). 


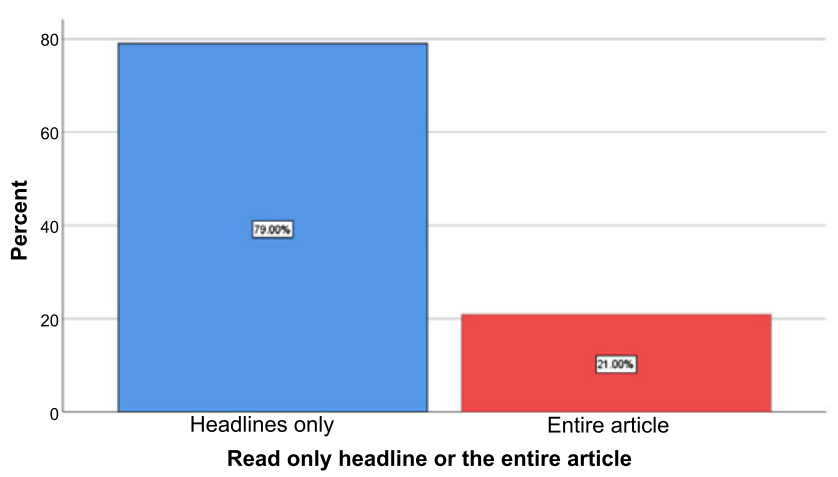

Figure 11: The bar chart represents the percentage distribution of response to the question of whether they read the headlines alone or the entire article read regarding COVID-19. X-axis denotes responses and Y-axis denotes the percentage of respondents. $79 \%$ of the participants read only the headlines (blue) while $21 \%$ of the participants read the entire article (red).

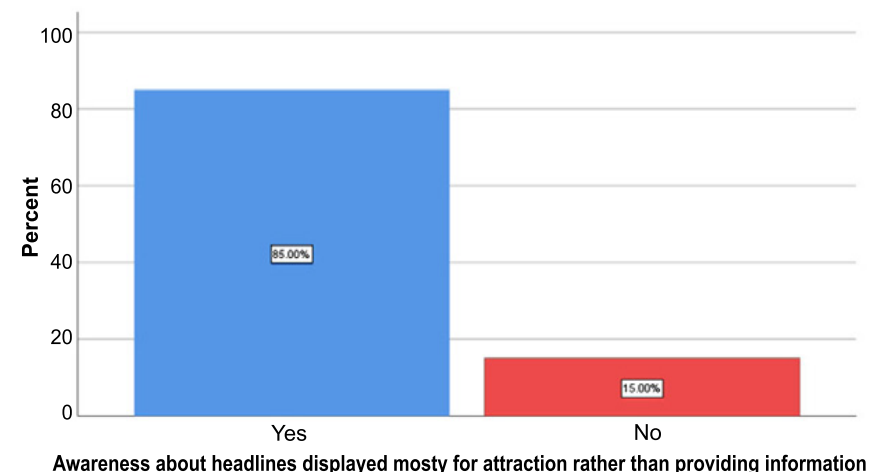

Figure 12: The bar chart represents the percentage distribution of awareness regarding the headlines displayed mostly for attraction rather than providing the information. X-axis denotes awareness about headlines displayed for attraction rather than providing information and $\mathrm{Y}$-axis denotes the percentage of respondents. $85 \%$ of the participants accepted that the headlines are displayed mostly for attraction rather than providing the information (blue) while $15 \%$ of the participants were unaware (red).

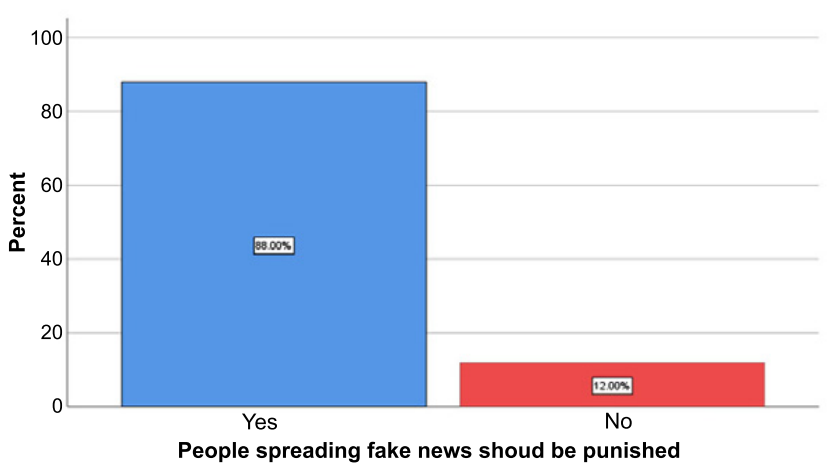

Figure 13: The bar chart represents the percentage distribution of response regarding the people spreading fake news that must be punished. $\mathrm{X}$-axis denotes responses and $\mathrm{Y}$-axis denotes the percentage of respondents. $88 \%$ of the participants agreed that people spreading fake news have to be punished (blue) while $12 \%$ of the participants did not agree (red).

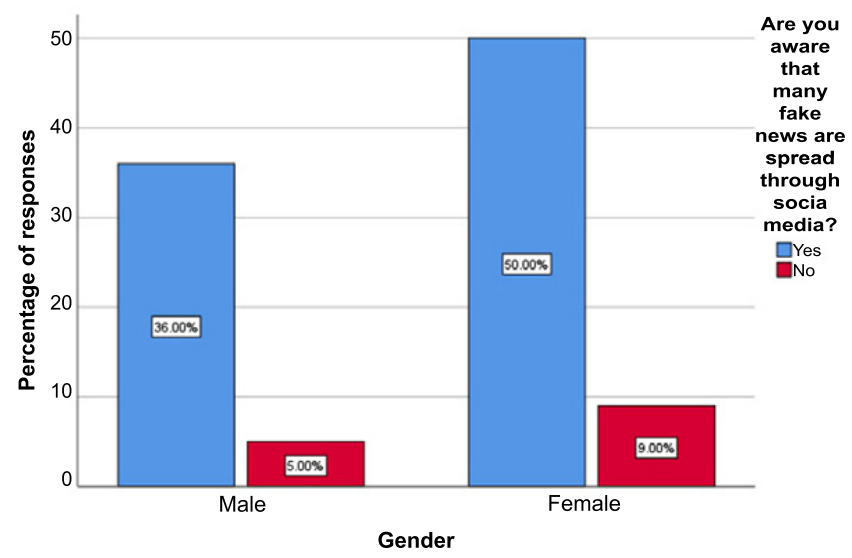

Figure 14: The Bar graph showing the association between gender and the news source used by the participants for news updates related to COVID-19. X-axis gender and the Y-axis represent the number of respondents. The response 'WhatsApp' is denoted by blue color and 'Facebook' is denoted by red color, 'other' is denoted by green color, 'Twitter' is denoted by yellow color. A higher number of females responded to WhatsApp when compared to other media sources than males. Chi-square test was done. $p=0.059(p>0.05)$ and it was found to be statistically not significant. 


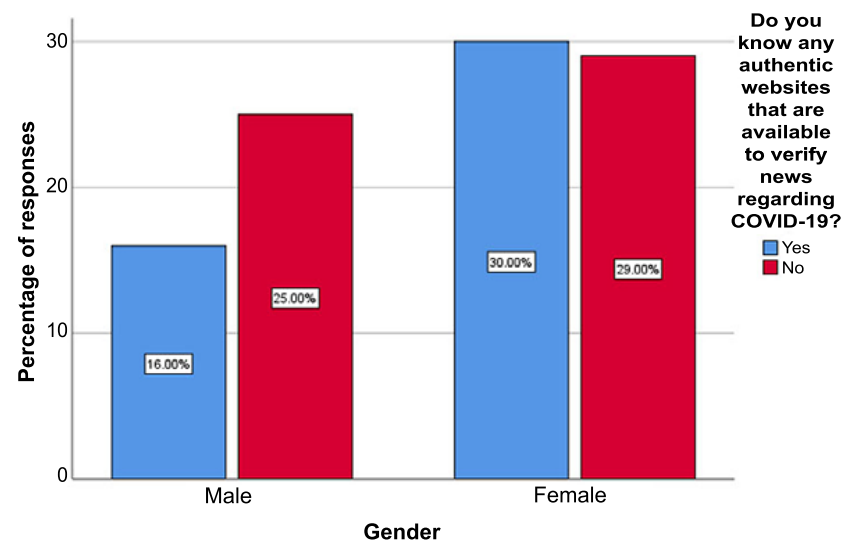

Figure 15: The Bar graph showing the association between gender and the awareness of authentic websites among the participants to verify news related to COVID-19. X-axis represents gender and $\mathrm{Y}$-axis represents the number of respondents. The response 'yes' is denoted by blue color and 'no' is denoted by red color. Females were more aware than males. Chi-square test was done. $p=0.243(p>0.05)$ and it was found to be statistically not significant.

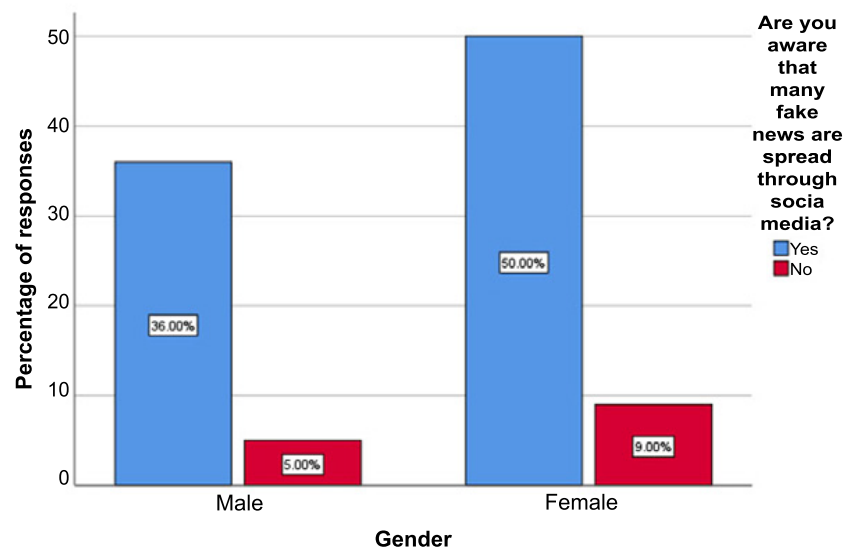

Figure 16: The Bar graph showing the association between gender and the awareness among the participants about the spread of fake news mostly through social media. X-axis represents gender and $\mathrm{Y}$-axis represents the number of respondents. The response 'yes' is denoted by blue color and 'no' is denoted by red color. Females were more aware than males. However, Chi-square test $p=0.665(p>0.05)$ and it was found to be statistically not significant.

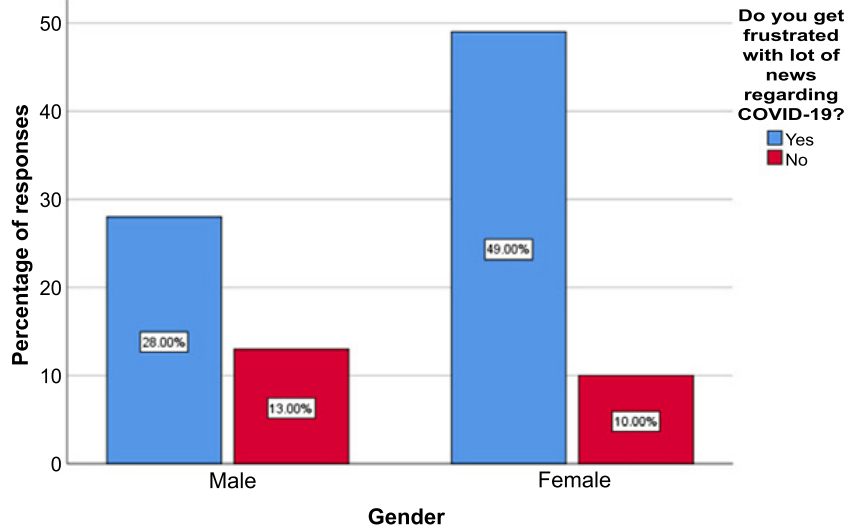

Figure 17: The Bar graph showing the association between gender and the frustration experienced due to numerous news updates related to COVID-19. X-axis represents gender and $\mathrm{Y}$-axis represents the percentage of responses. The response 'yes' is denoted by blue color and 'no' is denoted by red color. Females were more frustrated than males, Chi-square test was done. $p=0.085(p>0.05)$ and it was found to be statistically not significant. 